\title{
Draft genome sequence of Acinetobacter baumannii strain NCTC 13423, a multidrug- resistant clinical isolate
}

\author{
Joran E. Michiels ${ }^{1}$, Bram Van den Bergh ${ }^{1}$, Maarten Fauvart ${ }^{1,2}$ and Jan Michiels ${ }^{1 *}$
}

\begin{abstract}
Acinetobacter baumannii is a pathogen that is becoming increasingly important and causes serious hospitalacquired infections. We sequenced the genome of A. baumannii NCTC 13423, a multidrug-resistant strain belonging to the international clone II group, isolated from a human infection in the United Kingdom in 2003. The $3,937,944$ bp draft genome has a GC-content of $39.0 \%$ and a total of 3672 predicted protein-coding sequences. The availability of genome sequences of multidrug-resistant $A$. baumannii isolates will fuel comparative genomic studies to help understand the worrying spread of multidrug resistance in this pathogen.
\end{abstract}

Keywords: Draft genome, Acinetobacter baumannii, Nosocomial pathogen, Multidrug resistance, Human isolate Abbreviations: COG, Clusters of orthologous groups; PGAP, Prokaryotic genome annotation pipeline

\section{Introduction}

Acinetobacter baumannii recently emerged as an increasingly important pathogen causing healthcareassociated bloodstream, urinary tract, pulmonary, and device-related infections [1]. A. baumannii strains are often resistant against multiple antibiotics, owing to their high intrinsic resistance and a variety of acquired resistance mechanisms [2]. Carbapenem is usually an effective treatment choice, but carbapenem-resistant strains are globally on the rise, and alternative treatment options are limited [3].

Here, we present the draft genome sequence of $A$. baumannii NCTC 13423, a strain belonging to international clone lineage II isolated from a patient in a UK hospital in December 2003 [4]. NCTC 13423 shows resistance to ampicillin, amoxicillin-clavulanic acid, aztreonam, cefepime, cefotaxime, ceftazidime, cefoxitin, piperacillin, piperacillintazobactam, ciprofloxacin, gentamicin, and sulbactam [4]. Although originally reported as carbapenem-sensitive, a later report classified it to be also carbapenem-resistant [5]. Additionally, this strain is highly virulent and a strong biofilm producer [6].

\section{Organism information \\ Classification and features}

Bacteria in the genus Acinetobacter are Gram-negative, strictly aerobic, nonfermenting, nonmotile, catalasepositive, oxidase-negative coccobacilli [7] (Table 1). The genus Acinetobacter has gone through many taxonomic changes over the years, and the species $A$. baumannii has only been officially recognized since $1986[8,9]$. A. baumannii belongs to the family Moraxellaceae, order Pseudomonadales, class Gammaproteobacteria, and phylum Proteobacteria. Acinetobacter species are ubiquitous organisms, widely distributed in nature, and can be recovered from virtually any soil or water sample. However, A. baumannii seems to be an exception to this rule, as it currently has no known habitats except the hospital [10]. Microscopically, they are often observed as pairs of cells (Fig. 1). A. baumannii can withstand prolonged desiccation, allowing it to survive on dry surfaces and probably contributing to its persistent residence in hospital settings [11]. A phylogenetic tree based on $16 \mathrm{~S}$ rDNA sequences showed strong clustering with other $A$. baumannii strains (Fig. 2).

\footnotetext{
* Correspondence: jan.michiels@biw.kuleuven.be

${ }^{1}$ Centre of Microbial and Plant Genetics, KU Leuven, B-3001 Leuven, Belgium

Full list of author information is available at the end of the article
} 
Table 1 Classification and general features of Acinetobacter baumannii strain NCTC 13423 according to the MIGS recommendations [12]

\begin{tabular}{|c|c|c|c|}
\hline MIGS ID & Property & Term & $\begin{array}{l}\text { Evidence } \\
\text { code }^{\mathrm{a}}\end{array}$ \\
\hline & Classification & Domain Bacteria & TAS [29] \\
\hline & & Phylum Proteobacteria & TAS [30] \\
\hline & & Class Gammaproteobacteria & $\operatorname{TAS}[31,32]$ \\
\hline & & Order Pseudomonadales & $\operatorname{TAS}[33,34]$ \\
\hline & & Family Moraxellaceae & TAS [35] \\
\hline & & Genus Acinetobacter & $\operatorname{TAS}[34,36]$ \\
\hline & & Species Acinetobacter baumannii & TAS [8] \\
\hline & & Strain NCTC 13423 & NAS \\
\hline & Gram stain & Negative & TAS [8] \\
\hline & Cell shape & Coccobacillus & TAS [8] \\
\hline & Motility & Non-motile & TAS [37] \\
\hline & Sporulation & Non-sporulating & TAS [8] \\
\hline & $\begin{array}{l}\text { Temperature } \\
\text { range }\end{array}$ & Mesophilic & TAS [38] \\
\hline & $\begin{array}{l}\text { Optimum } \\
\text { temperature }\end{array}$ & $37^{\circ} \mathrm{C}$ & TAS [38] \\
\hline & $\begin{array}{l}\text { pH range; } \\
\text { Optimum }\end{array}$ & Unknown & NAS \\
\hline & $\begin{array}{l}\text { Carbon } \\
\text { source }\end{array}$ & $\begin{array}{l}\text { Chemoorganoheterotrophic; } \\
\text { citrate, lactate, ethanol, glutarate, } \\
\text { malate, aspartate, tyrosine, 2,3- } \\
\text { butanediol, 4-aminobutyrate }\end{array}$ & TAS [8] \\
\hline MIGS-6 & Habitat & Hospital & NAS \\
\hline MIGS-6.3 & Salinity & Unknown & NAS \\
\hline MIGS-22 & $\begin{array}{l}\text { Oxygen } \\
\text { requirement }\end{array}$ & Strictly aerobic & TAS [8] \\
\hline MIGS-15 & $\begin{array}{l}\text { Biotic } \\
\text { relationship }\end{array}$ & Free-living & TAS [8] \\
\hline MIGS-14 & Pathogenicity & Pathogenic & TAS [4] \\
\hline MIGS-4 & $\begin{array}{l}\text { Geographic } \\
\text { location }\end{array}$ & United Kingdom & TAS [4] \\
\hline MIGS-5 & $\begin{array}{l}\text { Sample } \\
\text { collection }\end{array}$ & $12 / 2003$ & TAS [4] \\
\hline MIGS-4.1 & Latitude & Unknown & NAS \\
\hline MIGS-4.2 & Longitude & Unknown & NAS \\
\hline MIGS-4.4 & Altitude & Unknown & NAS \\
\hline
\end{tabular}

aEvidence codes, IDA inferred from direct assay, TAS traceable author statement (i.e., a direct report exists in the literature), NAS non-traceable author statement (i.e., not directly observed for the living, isolated sample, but based on a generally accepted property for the species, or anecdotal evidence). These evidence codes are from the Gene Ontology project [39]

\section{Genome sequencing information}

\section{Genome project history}

The strain NCTC 13423 was isolated in 2003 in the United Kingdom from a repatriated casualty of the Iraq conflict [4], and was selected for sequencing because of its multidrug-resistant and virulence characteristics. Sequencing was carried out at the EMBL GeneCore facility

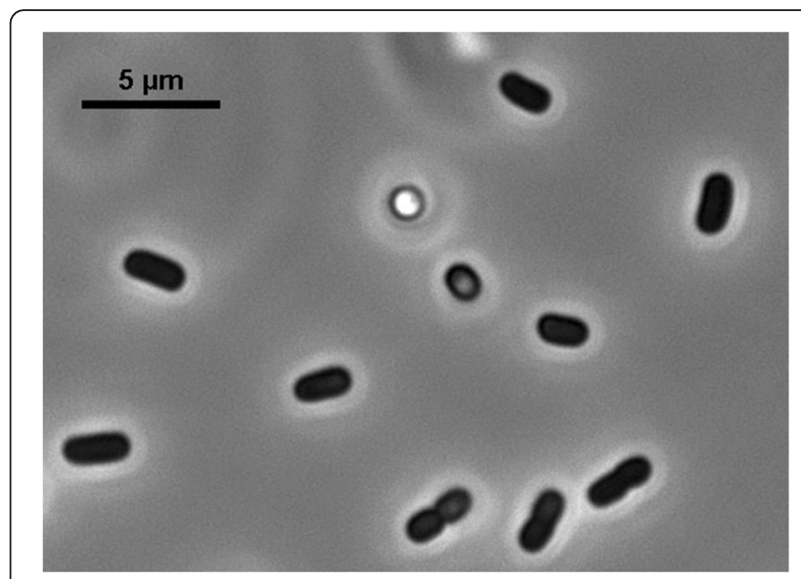

Fig. 1 Phase-contrast micrograph of A. baumannii NCTC 13423

(Heidelberg, Germany). Sequences were assembled using CLC Genomics Workbench (version 7.5.1) and annotated using NCBI's Prokaryotic Genome Annotation Pipeline (PGAP). This draft whole-genome sequence has been deposited at DDBJ/ENA/GenBank under the accession LOHD00000000. The project information, and its association with MIGS version 2.0 [12], is summarised in Table 2.

\section{Growth conditions and genomic DNA preparation}

Cultures for DNA isolation were inoculated from a single colony on LB agar in $5 \mathrm{ml}$ lysogeny broth and grown overnight at $37^{\circ} \mathrm{C}$ with orbital shaking (200 rpm). DNA was isolated using the DNeasy Blood\&Tissue Kit (Qiagen) following the manufacturer's instructions and pre-treatment protocol for Gram-negative bacteria. DNA concentration and purity were assessed using the Nanodrop ND-1000 spectrophotometer and Qubit fluorometer (ThermoFisher Scientific).

\section{Genome sequencing and assembly}

Sequencing was performed using the Nextera DNA Library Preparation Kit with the Illumina HiSeq 2000 platform (100 bp, paired-end) at the EMBL GeneCore facility (Heidelberg, Germany). The read library contained a total of 8,765,016 sequences in pairs. Sequence data was analysed using Qiagen's CLC Genomics Workbench (version 7.5.1). First, reads were trimmed for quality (score limit 0.05 ) and ambiguous nucleotides (maximum 2 ambiguities). Next, de novo assembly was performed (mismatch cost: 2, deletion cost: 3 , insertion cost: 3, length fraction: 0.5 , similarity fraction: 0.8), yielding 196 contigs (minimum length $200 \mathrm{bp}$ ) with an average coverage of 203x. Contigs averaged 20,092 bp in length (N50 of 111,328 bp). The total length of the 


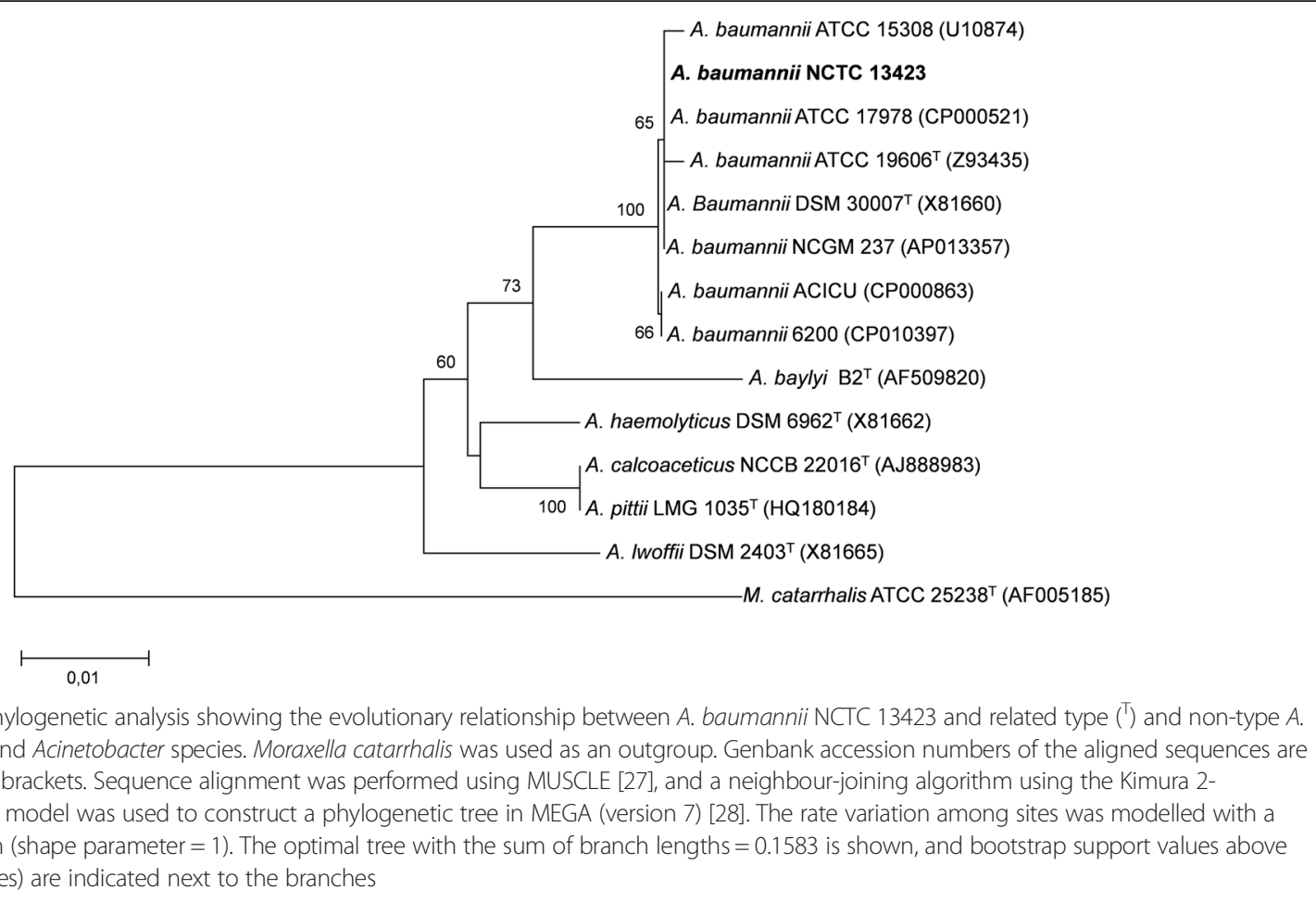

draft genome is $3,937,944$ bp with a GC-content of $39.0 \%$.

\section{Genome annotation}

All contigs were annotated using NCBI's Prokaryotic Genome Annotation Pipeline (PGAP). The Batch Web CDSearch Tool from NCBI [13] was used to identify Pfam domains [14] in the predicted protein sequences.

Table 2 Project information

\begin{tabular}{lll}
\hline MIGS ID & Property & Term \\
\hline MIGS-31 & Finishing quality & High-quality draft \\
MIGS-28 & Libraries used & $\begin{array}{l}\text { One paired-end Illumina } \\
\text { library (Nextera) }\end{array}$ \\
MIGS-29 & Sequencing platforms & Illumina HiSeq 2000 \\
MIGS-31.2 & Fold coverage & 203 \\
MIGS-30 & Assemblers & CLC NGS Cell 7.5.1 \\
MIGS-32 & Gene calling method & GeneMarkS+ \\
& Locus Tag & AUC58 \\
& Genbank ID & LOHD00000000 \\
& GenBank Date & 2016/02/26 \\
& of Release & \\
& GOLD ID & PRJNA305394 \\
& BIOPROJECT & NCTC 13423 \\
& Source Material & \\
Identifier & Project relevance & Medical \\
\hline
\end{tabular}

Classification of predicted proteins in Clusters of Orthologous Groups (COG) functional categories [15] was done with the WebMGA web server for metagenomic analysis [16]. Signal peptides, transmembrane domains, and CRISPR repeats were predicted using the SignalP 4.1 server [17], the TMHMM server [18], and the CRISPRFinder tool [19], respectively. Only confirmed and not questionable CRISPR hits were taken into account.

\section{Genome properties}

Table 3 summarises the properties of the draft genome. Reads were assembled into 196 contigs, totalling $3,937,944$ bp with a $39.0 \%$ GC-content. PGAP predicted a total number of 3875 genes, including 3672 protein coding genes (totalling 3,384,768 base pairs), 135 pseudo genes, and 68 RNA genes (64 tRNA, 3 rRNA, and 1 ncRNA). $75.17 \%$ of the protein-coding genes had a putative function assigned, the remainder was annotated as a hypothetical protein. Additional characteristics of the predicted genes are given in Table 3, and Table 4 shows their distribution amongst the different functional COG categories.

\section{Insights from the genome sequence}

Functional analysis of the genome sequence by RAST annotation [20] revealed A. baumannii ACICU as the closest related sequenced neighbor. A. baumannii ACICU is an epidemic, multidrug-resistant strain isolated from a hospital 
Table 3 Genome statistics

\begin{tabular}{lll}
\hline Attribute & Value & \% of Total \\
\hline Genome size (bp) & $3,937,944$ & 100 \\
DNA coding (bp) & $3,384,768$ & 85.95 \\
DNA G + C (bp) & $1,537,664$ & 39.05 \\
DNA scaffolds & 196 & 100 \\
Total genes & 3875 & 100 \\
Protein coding genes & 3672 & 94.76 \\
RNA genes & 68 & 1.75 \\
Pseudo genes & 135 & 3.48 \\
Genes in internal clusters & - & - \\
Genes with function prediction & 2913 & 75.17 \\
Genes assigned to COGs & 3174 & 81.91 \\
Genes with Pfam domains & 3,002 & 77.47 \\
Genes with signal peptides & 313 & 8.08 \\
Genes with transmembrane helices & 882 & 22.76 \\
CRISPR repeats & 0 & -
\end{tabular}

outbreak in Rome [21]. The high genetic relatedness between A. baumannii ACICU and A. baumannii NCTC 13423 was confirmed by calculating their two-way average amino acid identity (AAI), which was $99.30 \%$ based on 3360 protein sequences [22]. Indicative for the multidrug-resistant phenotype, annotations by RAST included six different $\beta$-lactamase enzymes, among which two AmpC-type $\beta$-lactamases (class $\mathrm{C}$ ), a metallo- $\beta$-lactamase (class B), two class A $\beta$ lactamases (of which one TEM-type broad-spectrum $\beta$-lactamase) and an oxa-51 like carbapenemase (class D). Using TAfinder, a web-based tool to identify type II toxin-antitoxin (TA) loci in bacterial genomes [23], we predicted the presence of 12 type II TA modules in the A. baumannii NCTC 13423 draft genome. Considering only TAfinder hits with normalized homology scores $(\mathrm{H}$-value $)>0.5$, five $\mathrm{pu}-$ tative TA modules remain, three of which are also present in the genome of $A$. baumannii ACICU. Interestingly, $A$. baumannii has been reported to form antibiotic-tolerant persister cells [24, 25], and these TA modules might play a role in their formation [26].

\section{Conclusions}

We determined the draft genome sequence of the highly virulent, multidrug-resistant A. baumannii NCTC 13423 clinical isolate. The availability of genomic sequences of clinical $A$. baumannii isolates from a variety of locations and sources will benefit comparative genomic studies to better understand the worrying spread of multidrug resistance in this pathogen.
Table 4 Number of genes associated with general COG functional categories

\begin{tabular}{llrll}
\hline Code & Value & \%age & Description \\
\hline J & 177 & 4.82 & Translation, ribosomal structure and biogenesis \\
A & 1 & 0.03 & RNA processing and modification \\
K & 272 & 7.41 & Transcription \\
L & 125 & 3.40 & Replication, recombination and repair \\
B & 0 & 0.00 & Chromatin structure and dynamics \\
D & 32 & 0.87 & Cell cycle control, Cell division, chromosome \\
& & & partitioning \\
V & 40 & 1.09 & Defense mechanisms \\
T & 97 & 2.64 & Signal transduction mechanisms \\
M & 193 & 5.26 & Cell wall/membrane biogenesis \\
N & 42 & 1.14 & Cell motility \\
U & 88 & 2.40 & Intracellular trafficking and secretion \\
O & 112 & 3.05 & Posttranslational modification, protein \\
& & & turnover, chaperones \\
C & 202 & 5.50 & Energy production and conversion \\
G & 138 & 3.76 & Carbohydrate transport and metabolism \\
E & 288 & 7.84 & Amino acid transport and metabolism \\
F & 81 & 2.21 & Nucleotide transport and metabolism \\
H & 131 & 3.57 & Coenzyme transport and metabolism \\
I & 182 & 4.96 & Lipid transport and metabolism \\
P & 185 & 5.04 & Inorganic ion transport and metabolism \\
Q & 97 & 2.64 & Secondary metabolites biosynthesis, \\
& & & transport and catabolism \\
R & 406 & 11.06 & General function prediction only \\
S & 285 & 7.76 & Function unknown \\
- & 498 & 13.56 & Not in CoGs \\
\hline The tota is & & & \\
& & &
\end{tabular}

The total is based on the total number of protein coding genes in the genome

\section{Acknowledgements}

JEM and BVDB are recipients of a fellowship from the Agency for Innovation by Science and Technology (IWT) and the Research Foundation Flanders (FWO), respectively. This work was supported by grants from the KU Leuven Research Council (PF/10/010 "NATAR", IDO/09/01), the Interuniversity Attraction Poles program initiated by the Belgian Science Policy Office (IAP P7/28) and the FWO (grants G.0413.10, G.0471.12 N, G.0B25.15 N). The funders had no role in study design, data collection and interpretation, or the decision to submit the work for publication.

\section{Authors' contributions}

JEM performed the experiments, analysed the data, and wrote the manuscript. BVDB and MF helped analysing the data and edited the manuscript. JM initiated and supervised the study, and edited the manuscript. All authors read and approved the final manuscript.

\section{Competing interests}

The authors declare that they have no competing interests.

\section{Author details}

${ }^{1}$ Centre of Microbial and Plant Genetics, KU Leuven, B-3001 Leuven, Belgium. ${ }^{2}$ Smart Systems and Emerging Technologies Unit, Department of Life Science Technologies, imec, B-3001 Leuven, Belgium.

Received: 21 March 2016 Accepted: 19 August 2016 Published online: 01 September 2016 


\section{References}

1. Antunes LCS, Visca P, Towner KJ. Acinetobacter baumannii: evolution of a global pathogen. Pathog Dis. 2014;71:292-301.

2. Potron A, Poirel L, Nordmann P. Emerging broad-spectrum resistance in Pseudomonas aeruginosa and Acinetobacter baumannii: mechanisms and epidemiology. Int J Antimicrob Agents. 2015;45:568-85.

3. Viehman JA, Nguyen MH, Doi Y. Treatment options for carbapenemresistant and extensively drug-resistant Acinetobacter baumannii infections. Drugs. 2014;74:1315-33.

4. Turton JF, Kaufmann ME, Gill MJ, Pike R, Scott PT, Fishbain J, et al. Comparison of Acinetobacter baumannii isolates from the United Kingdom and the United States that were associated with repatriated casualties of the Iraq conflict. J Clin Microbiol. 2006:44:2630-4.

5. Merabishvili M, Vandenheuvel D, Kropinski AM, Mast J, De Vos D, Verbeken $\mathrm{G}$, et al. Characterization of newly isolated lytic bacteriophages active against Acinetobacter baumannii. PLoS One. 2014;9:e104853.

6. Wand ME, Bock $L$, Turton JF, Nugent PG, Sutton JM. Acinetobacter baumannii virulence is enhanced in Galleria mellonella following biofilm adaptation. J Med Microbiol. 2012:61:470-7.

7. Towner KJ. Acinetobacter: an old friend, but a new enemy. J Hosp Infect. 2009;73:355-63.

8. Bouvet PJM, Grimont PAD. Taxonomy of the genus Acinetobacter with the recognition of Acinetobacter baumannii sp. nov. Acinetobacter haemolyticus sp. nov., Acinetobacter johnsonii sp. nov., and Acinetobacter junii sp. nov. and emended descriptions of Acinetobacter calcoaceticus and Acinetobacter Iwofii. Int J Syst Bacteriol. 1986;36:228-40.

9. Chan JZ-M, Halachev MR, Loman NJ, Constantinidou C, Pallen MJ. Defining bacterial species in the genomic era: insights from the genus Acinetobacter. BMC Microbiol. 2012;12:302.

10. Peleg AY, Seifert $H$, Paterson DL. Acinetobacter baumannii: emergence of a successful pathogen. Clin Microbiol Rev. 2008;21:538-82.

11. Jawad A, Seifert $H$, Snelling AM, Heritage J, Hawkey PM. Survival of Acinetobacter baumannii on dry surfaces: comparison of outbreak and sporadic isolates. J Clin Microbiol. 1998;36:1938-41.

12. Field D. The minimum information about a genome sequence (MIGS) specification. Nat Biotechnol. 2008:26:541-7.

13. Marchler-Bauer A, Derbyshire MK, Gonzales NR, Lu S, Chitsaz F, Geer LY, et al. CDD: NCBI's conserved domain database. Nucleic Acids Res. 2015:43: D222-6.

14. Finn RD, Coggill P, Eberhardt RY, Eddy SR, Mistry J, Mitchell AL, et al. The Pfam protein families database: towards a more sustainable future. Nucleic Acids Res. 2015:44:D279-85.

15. Galperin MY, Makarova KS, Wolf YI, Koonin EV. Expanded microbial genome coverage and improved protein family annotation in the COG database. Nucleic Acids Res. 2015;43:D261-9.

16. Wu S, Zhu Z, Fu L, Niu B, Li W. WebMGA: a customizable web server for fast metagenomic sequence analysis. BMC Genomics. 2011;12:444

17. Petersen TN, Brunak S, von Heijne G, Nielsen H. SignalP 4.0: discriminating signal peptides from transmembrane regions. Nat Methods. 2011:8:785-6.

18. Krogh A, Larsson B, von Heijne G, Sonnhammer EL. Predicting transmembrane protein topology with a hidden Markov model: application to complete genomes. J Mol Biol. 2001;305:567-80

19. Grissa I, Vergnaud G, Pourcel C. CRISPRFinder: a web tool to identify clustered regularly interspaced short palindromic repeats. Nucleic Acids Res. 2007;35:52-7.

20. Overbeek R, Olson R, Pusch GD, Olsen GJ, Davis JJ, Disz T, et al. The SEED and the rapid annotation of microbial genomes using subsystems technology (RAST). Nucleic Acids Res. 2014;42:D206-14.

21. lacono M, Villa L, Fortini D, Bordoni R, Imperi F, Bonnal RJP, et al. Wholegenome pyrosequencing of an epidemic multidrug-resistant Acinetobacter baumannii strain belonging to the European clone II group. Antimicrob Agents Chemother. 2008:52:2616-25.

22. Rodriguez-R LM, Konstantinidis KT. The enveomics collection: a toolbox for specialized analyses of microbial genomes and metagenomes. PeerJ Prepr. 2016;4:e1900v1.

23. Shao Y, Harrison EM, Bi D, Tai C, He X, Ou HY, et al. TADB: a web-based resource for type 2 toxin-antitoxin loci in bacteria and archaea. Nucleic Acids Res. 2011;39:606-11.

24. Michiels JE, Van den Bergh B, Verstraeten N, Fauvart M, Michiels J. In vitro emergence of high persistence upon periodic aminoglycoside challenge in the ESKAPE pathogens. Antimicrob Agents Chemother. 2016;60(8):4630-7.
25. Barth VC, Rodrigues BÁ, Bonatto GD, Gallo SW, Pagnussatti VE, Ferreira CAS, et al. Heterogeneous persister cells formation in Acinetobacter baumannii. PLoS One. 2013;8:e84361.

26. Maisonneuve $\mathrm{E}$, Gerdes K. Molecular mechanisms underlying bacterial persisters. Cell. 2014;157:539-48.

27. Edgar RC. MUSCLE: a multiple sequence alignment method with reduced time and space complexity. BMC Bioinf. 2004:5:113.

28. Kumar S, Stecher G, Tamura K. MEGA7: molecular evolutionary genetics analysis version 7.0 for bigger datasets. Mol Biol Evol. 2016;33:1870-4.

29. Woese CR, Kandler O, Wheelis ML. Towards a natural system of organisms: proposal for the domains Archaea, Bacteria, and Eucarya. Proc Natl Acad Sci. 1990;87:4576-9.

30. Garrity G, Bell J, Lilburn T. Phylum XIV. Proteobacteria phyl. nov. In: Brenne DJ, Krieg NR, Staley JT, Garrity GM, editors. Bergey's manual of systematic bacteriology.Vol 2. New York: Springer; 2005. p. 1.

31. Garrity G, Bell J, Lilburn T. Class III. Gammaproteobacteria class. nov. In: Brenner DJ, Krieg NR, Staley JT, Garrity GM, editors. Bergey's manual of systematic bacteriology.Vol 2. New York: Springer; 2005. p. 1.

32. List editor. Validation of publication of new names and new combinations previously effectively published outside the IJSEM. List no. 106. Int. J. Syst. Evol. Microbiol. 2005;55:2235.

33. Orla-Jensen S. The main lines of the natural bacterial system. J Bacteriol. 1921;6:263.

34. Skerman V, McGowan V, Sneath P. Approved lists of bacterial names. Int J Syst Bacteriol. 1980;30:225-420

35. Rossau R, Van Landschoot A, Gillis M, De Ley J. Taxonomy of Moraxellaceae fam. nov., a new bacterial family to accommodate the genera Moraxella, Acinetobacter, and Psychrobacter and related organisms. Int J Syst Bacteriol. 1991:41:310-9.

36. Brisou J, Prévot AR. Études de systématique bactérienne. X. Révision des espèces réunies dans le genre Achromobacter. Ann Inst Pasteur (Paris). 1954; $86: 722$.

37. Von Graevenitz A. Acinetobacter, Alcaligenes, Moraxella, and other nonfermentative Gram-negative bacteria. In: Murray PR, Barron JE, Pfaller MA, Tenover FC, Yolken RH, editors. Manual of clinical microbiology. Washington: ASM Press; 1995. p. 520-32.

38. Visca $\mathrm{P}$, Seifert $H_{1}$, Towner KJ. Acinetobacter infection - an emerging threat to human health. IUBMB Life. 2011;63:1048-54.

39. Ashburner M, Ball CA, Blake JA. Gene ontology: tool for the unification of biology. Nat Genet. 2000;25:25-9.

\section{Submit your next manuscript to BioMed Central and we will help you at every step:}

- We accept pre-submission inquiries

- Our selector tool helps you to find the most relevant journal

- We provide round the clock customer support

- Convenient online submission

- Thorough peer review

- Inclusion in PubMed and all major indexing services

- Maximum visibility for your research

Submit your manuscript at www.biomedcentral.com/submit 